\title{
Low Temperature Brittleness of Asphalts
}

\author{
Kenji Murayama,* Takeshige Fukushima* and Yoshio Fukuda*
}

(Received December 20, 1958)

\section{Summary}

Flow properties of the asphalts made from eight sources were examined by Traxler viscometer at their softening temperatures, and it was found that the characters of these samples were roughly classified into two types, i.e., sol-type and gel-type, corresponding to the degree of complex flow.

Ductilities at 25,15 and $10^{\circ} \mathrm{C}$. of sol-type asphalts were larger than those of gel-type ones.

Brittle strengths of the same asphalts were measured by a modified Instron rheometer at the tensile velocity of $8 \mathrm{~mm} / \mathrm{sec}$. The strengths of sol-type asphalts were smaller than those of gel-type ones at least at $0^{\circ} \mathrm{C}$.

Critical temperatures at which elongation occured under the tensile velocity mentioned above were higher for sol-type asphalts than for gel-type ones.

From these two phenomena, it was found that good ductilities at low temperature were accompanied by sol-type character of asphalts, but it did not necessarily indicate good mechanical property at low temperature.

\section{Introduction}

For evaluating the asphalt quality, usually the three long estabilished testing methods for penetration, softening point, and ductility have been used. However, many correlations between the properties determind by the methods and practical performances have not been established. Particularly, the significance of ductility at low temperatures which was recently adopted by JIS for paving grade should be more profoundly considered.

In general, the measurement of ductility evalu-

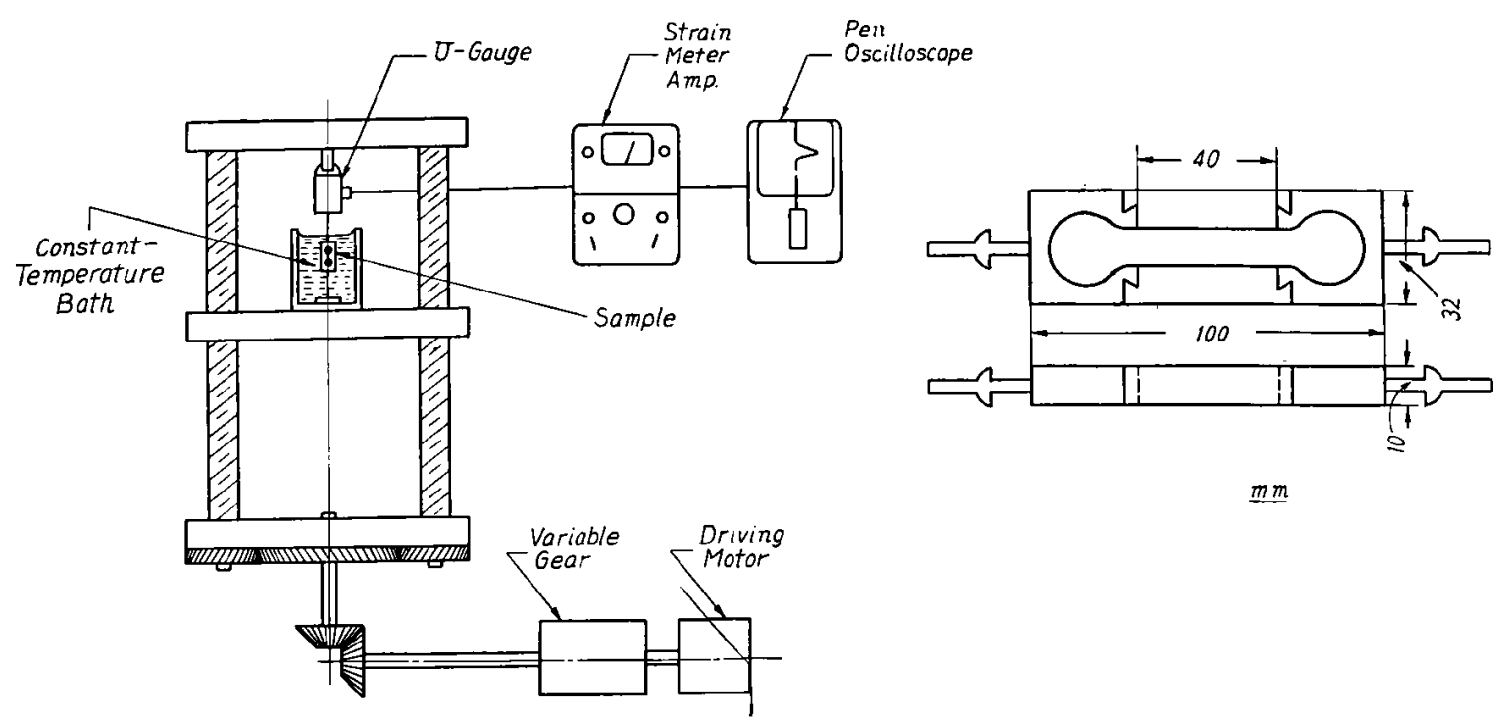

Fig. 1 Instrument and sample mould for determination of rupture strength.

* Cent. Tech. Res. Lab., Nippon Oil Co., Yokohama, Japan. 
ates elongation rupture at low speed and for large deformation, which conditions are considerably different from those met in practice. Brittleness rupture at high velocity and smaller deformation seems to be more practical. Therefore, we shall principally discuss rupture strength at low temperatures. At the same time, colloidal structure of asphalt is postulated from a view point of rheology, and its relationship with rupture strength is discussed.

\section{Measurements}

The rate of deformation, the temperature as well as the shape and conditions of preparation of the test piece will affect the phenomenon of rupture in asphalt. When the properties of asphalt change with time, the effects of aging should not be neg- lected. In our research the measurements of rupture strength $\left(\mathrm{kg} / \mathrm{cm}^{2}\right)$ were made at a deformation rate of $8 \mathrm{~mm} / \mathrm{sec}$, and at $0^{\circ} \mathrm{C}$, considering the limitations at the instrument and the practical asphalt paving conditions. Other conditions were kept as constant as possible.

To determine the rupture strength, a tension tester as shown in Fig. 1 was used. A sample of fused asphalt is casted in a mould, cooled to the room temperature, and inserted vertically between the bottom of the thermostat and a U-gauge which is hung from the cross head. Keeping the temperature of the sample at a definite temperature by circulating water or ethylene glycol, the mould frame is removed. Simultaneously with the start of recording with a pen-oscilloscope, the sample is

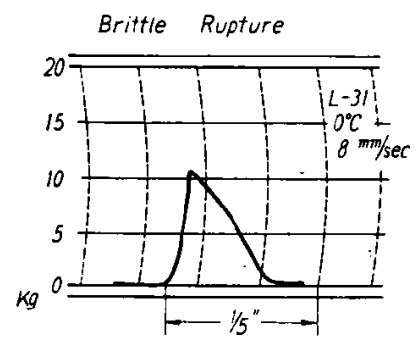

Elongate Rupture

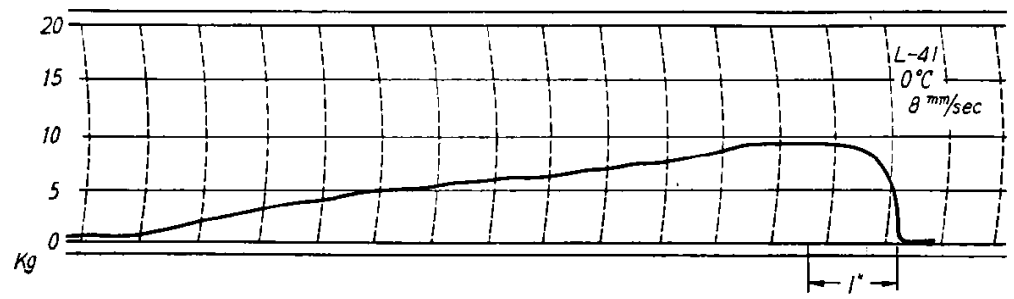

Fig. 2 Records by pen ocilloscope.

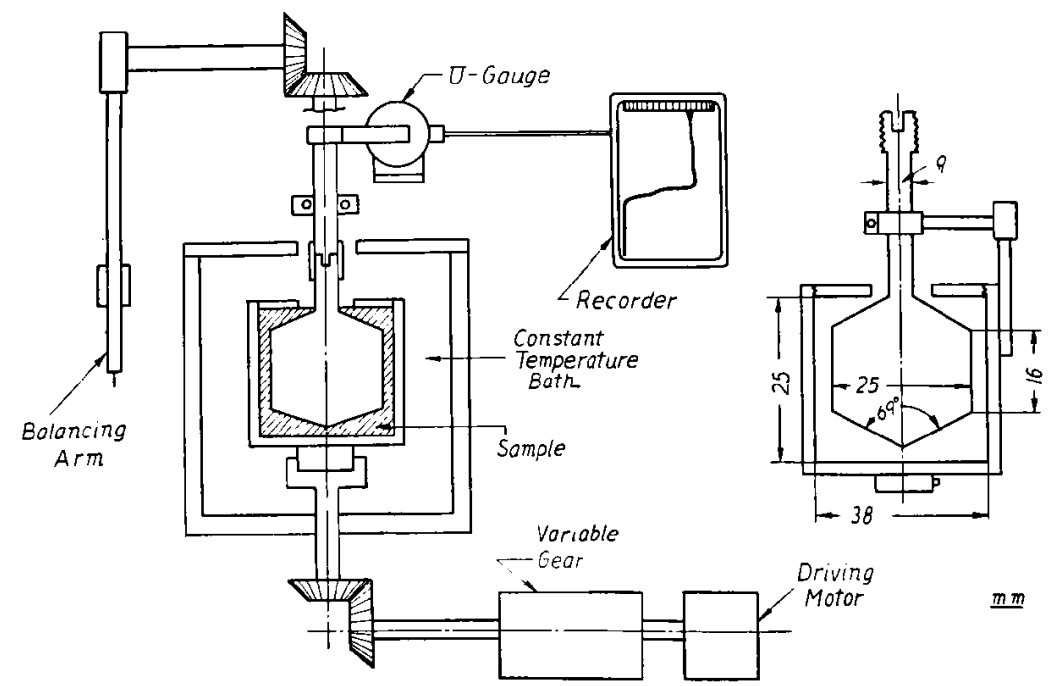

Fig. 3 Traxler viscometer. 
pulled downward by motor, and the state of rupture is observed.

In the case of brittleness rupture, the sectional surface is flat and almost vertical to the direction of pulling, and it takes about 1,10 second to complete the rupture. On the other hand, the ruptured part becomes like a spindle in the case of elongation rupture, and the time required is in the order of seconds. The strength diagrams of the two types of rupture are clearly different as shown in Fig. 2.

A viscometer of the Traxler type (1) is used to measure fluidity, and a relation between shearing rate (r.p.h. of the outer cylinder) and shearing stress (torque at the central axis) is obtained at the softening point. Plotting both numbers in a log-scale, the inclination of the straight line is expressed as the degree of complex flow "C".

Sketches of the instrument and the cell are shown in Fig. 3, and a record of measurements is given in Fig. 4.

\section{Results Obtained}

Four penetration grades of asphalt were prepared, respectively, by semi-blowing Asahigawa, Kurokawa, Higashiyama, and Arabian light and heavy residues. General properties, the rupture strength at $0^{\circ} \mathrm{C}$, and " $\mathrm{C}$ " of the samples are listed in Table 1, and the dependence of temperature on brittleness is shown in Fig. 5 .

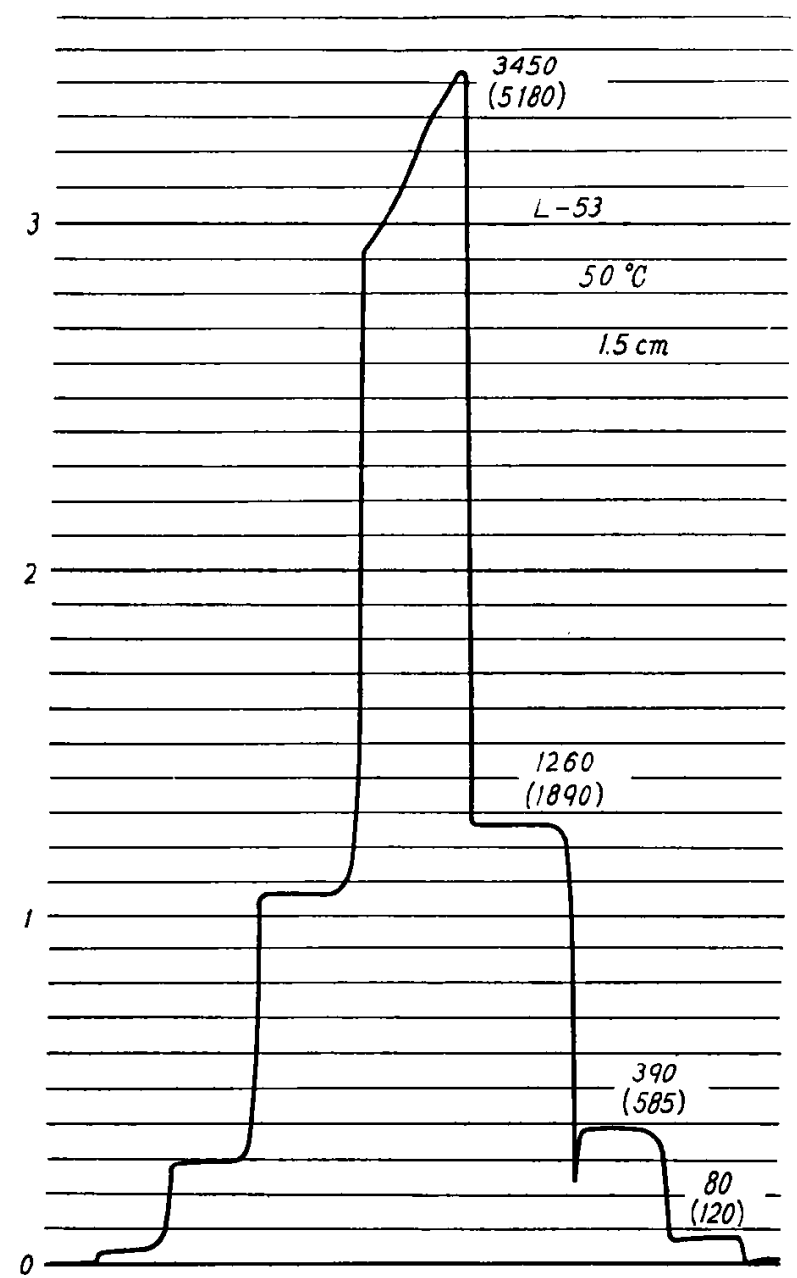

kg

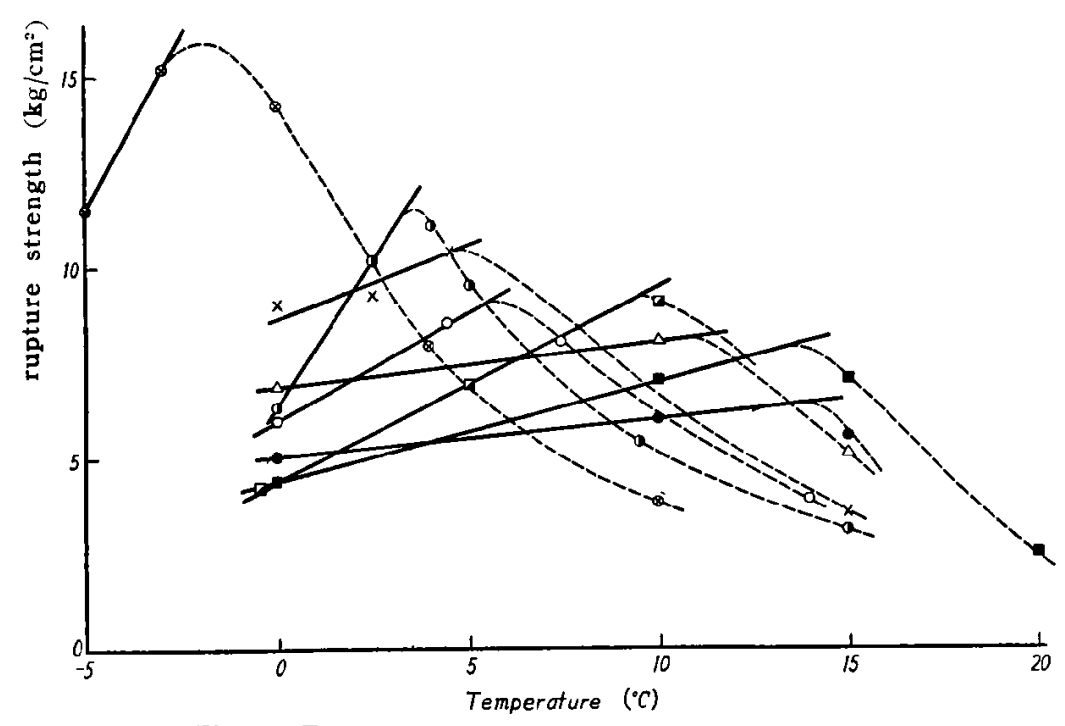

Fig. 5 Temperature dependance on rupture strength. 
Table 1

\begin{tabular}{|c|c|c|c|c|c|c|c|c|c|c|}
\hline \multirow{2}{*}{$\begin{array}{c}\text { Sample } \\
\text { No. }\end{array}$} & \multicolumn{2}{|c|}{ Source } & \multirow{2}{*}{$\begin{array}{c}\text { Soft. Pt. } \\
\left(\mathrm{R} \& \mathrm{~B},{ }^{\circ} \mathrm{C}\right)\end{array}$} & \multirow{2}{*}{$\begin{array}{l}\text { Pen. } \\
\left(25^{\circ} \mathrm{C}\right. \\
100 \mathrm{~g} / 5 \mathrm{sec})\end{array}$} & \multicolumn{3}{|c|}{ Duc. (cm) } & \multirow[b]{2}{*}{ P.I. } & \multirow{2}{*}{$\begin{array}{c}\text { Rupture } \\
\text { Strength } \\
0^{\circ} \mathrm{C}, \mathrm{kg} / \mathrm{cm}^{2}\end{array}$} & \multirow{2}{*}{$\begin{array}{l}\text { Complex } \\
\text { Flow "C" } \\
\text { @ S.P. }\end{array}$} \\
\hline & $\begin{array}{l}\text { Blowing } \\
\text { Stock }\end{array}$ & $\begin{array}{l}\text { Vis. RIS } \\
\text { (a) } 100^{\circ} \mathrm{C}\end{array}$ & & & $25^{\circ} \mathrm{C}$ & $15^{\circ} \mathrm{C}$ & $10^{\circ} \mathrm{C}$ & & & \\
\hline $\mathrm{L}-38$ & \multirow{4}{*}{$\begin{array}{l}\text { Asahigawa } \\
\cdots \mathrm{L}\end{array}$} & \multirow{4}{*}{1040} & 46.0 & 101 & 144 & 77.5 & 17 & -0.4 & 6 & 0.85 \\
\hline $\mathrm{L}-37$ & & & 57.0 & 49 & 36 & - & - & +0.4 & 9 & 0.79 \\
\hline L-35 & & & 70.5 & 30 & 4.9 & - & - & +1.7 & 12 & 0.56 \\
\hline L-36 & & & 109.5 & 14 & 1.6 & - & - & +4.8 & 7 & 0.36 \\
\hline L-32 & \multirow{4}{*}{$\begin{array}{c}\text { Asahigawa } \\
\cdots \mathrm{H}\end{array}$} & \multirow{4}{*}{2775} & 43.7 & 107 & $150+$ & $150+$ & $150+$ & -1.0 & 9 & 0.90 \\
\hline $\mathrm{L}-31$ & & & 51.4 & 52 & $150+$ & 11.5 & - & -0.7 & 11 & 0.87 \\
\hline $\mathrm{L}-33$ & & & $59 \cdot 4$ & 32.5 & 93 & - & - & +1.8 & 8 & 0.81 \\
\hline $\mathrm{L}-34$ & & & 88.0 & 14 & 3 & - & - & +2.6 & 7 & 0.61 \\
\hline L-41 & \multirow{4}{*}{$\begin{array}{l}\text { Arabia } \\
\cdots \mathrm{L} \\
\cdots \otimes \cdots\end{array}$} & \multirow{4}{*}{952} & 51.7 & 90 & 55 & 9 & 7 & +0.8 & $(13)^{*}$ & 0.76 \\
\hline$L-40$ & & & 64.5 & 52 & 7.7 & - & - & +2.0 & 10 & 0.64 \\
\hline L-39 & & & 94.5 & 27.5 & 2.5 & - & - & +4.6 & 12 & 0.40 \\
\hline $\mathrm{L}-42$ & & & 127.5 & 15 & 2 & - & - & +6.4 & 10 & 0.29 \\
\hline $\mathrm{L}-46$ & Arabia & \multirow{4}{*}{2425} & 48.2 & 91 & $150+$ & 44.5 & 12.5 & -0.1 & 9 & 0.82 \\
\hline $\mathrm{L}-45$ & \multirow{3}{*}{$\cdots \mathrm{H}$} & & 57.8 & 52 & 7.2 & - & - & +0.6 & 8 & 0.72 \\
\hline L-44 & & & 69.5 & 32 & 6.5 & - & - & +1.8 & 7 & 0.71 \\
\hline $\mathrm{L}-47$ & & & 108 & 14 & 2.8 & - & - & +4.6 & 6 & 0.50 \\
\hline $\mathrm{L}-49$ & \multirow{4}{*}{$\begin{array}{l}\text { Kurokawa } \\
\cdots \mathrm{L} \\
\cdots \mathrm{D} \cdots\end{array}$} & \multirow{4}{*}{933} & 45.4 & 107 & $150+$ & 109 & 37.5 & -0.4 & 6 & 0.92 \\
\hline $\mathrm{L}-50$ & & & 58.5 & 49 & 24 & - & - & +0.6 & 6 & 0.70 \\
\hline $\mathrm{L}-43$ & & & 72.7 & 30.5 & 4.8 & - & - & +2.0 & 6 & 0.58 \\
\hline L-48 & & & 110 & 12.5 & 2 & - & - & +4.6 & 6 & 0.38 \\
\hline $\mathrm{L}-63$ & \multirow{4}{*}{$\begin{array}{l}\text { Kurokawa } \\
\ldots \mathrm{H} \\
\ldots\end{array}$} & \multirow{4}{*}{2476} & 44.1 & 90 & $150+$ & $150+$ & $150+$ & -1.4 & 5 & 0.99 \\
\hline $\mathrm{L}-60$ & & & 52.8 & 49 & $150+$ & 10 & - & -0.6 & 4 & 0.92 \\
\hline L-59 & & & 65.0 & 28 & 13.8 & - & - & +0.5 & 5 & 0.74 \\
\hline $\mathrm{L}-62$ & & & 95.0 & 13.5 & 1.5 & - & - & +3.2 & 4 & 0.59 \\
\hline $\mathrm{L}-58$ & \multirow{4}{*}{$\begin{array}{l}\text { Higashiya- } \\
\text { ma } \\
\cdots \mathrm{L}\end{array}$} & \multirow{4}{*}{1137} & 44.4 & 101 & $150+$ & $150+$ & 96.5 & -1.0 & 5 & 1.00 \\
\hline $\mathbf{L}-55$ & & & 52.0 & 50 & $150+$ & 10 & - & -0.7 & 6 & 0.93 \\
\hline L-57 & & & 61.6 & 30.5 & 31.5 & - & - & +0.5 & 5 & 0.87 \\
\hline $\mathrm{L}-56$ & & & 92.5 & 13.5 & 2 & - & - & +3.1 & 5 & 0.78 \\
\hline L-52 & $\begin{array}{l}\text { Higashiya- } \\
\text { ma }\end{array}$ & \multirow{4}{*}{2377} & 42.5 & 110 & $150+$ & $150+$ & $150+$ & -1.3 & 5 & 1.01 \\
\hline $\mathbf{L}-53$ & $\cdots \mathbf{H} \cdots$ & & 49.7 & 49 & $150+$ & 98 & - & -1.3 & 5 & 0.92 \\
\hline $\mathbf{L}-54$ & & & 73.3 & 14 & 5 & - & - & +0.7 & 4 & 0.78 \\
\hline L-51 & $-\square-$ & & 77.8 & 11.5 & 4.5 & - & - & +0.8 & 3 & 0.75 \\
\hline M-5 & \multirow{6}{*}{\multicolumn{2}{|c|}{$\begin{array}{l}\text { Molecular Distillation } \\
\text { " " } \\
\text { Solvent Extraction } \\
\text { " " } \\
\text { Blowing after Blending } \\
\text { " }\end{array}$}} & 44.0 & 100 & $150+$ & $150+$ & 10 & -1.0 & 5 & - \\
\hline M-4 & & & 48.5 & 65 & $150+$ & $150+$ & 127 & -0.8 & 5 & - \\
\hline BW-78 & & & 43.5 & 98 & $150+$ & $150+$ & 70 & -1.4 & 5 & - \\
\hline BW-79 & & & 43.4 & 101.5 & $150+$ & $150+$ & 94 & -1.0 & 6 & - \\
\hline $\mathrm{L}-70-4$ & & & 44.2 & 99 & -- & $150+$ & $150+$ & -1.0 & 4 & - \\
\hline 219 & & & 44.1 & 115 & - & $150+$ & $150+$ & -0.4 & 3 & - \\
\hline
\end{tabular}

* Elongation Rupture

In Fig. 6, fluidity of the lower S.P. asphalt of each series is shown. In Fig. 7 the logarithmic relation between shearing stress and rate of shear is shown. The relation between " $\mathrm{C}$ " and soften- ing point can be seen in Fig. 8. The rupture strength at $0^{\circ} \mathrm{C}$ seems to vary according to S.P., though it is not certain due to a lack of data. 


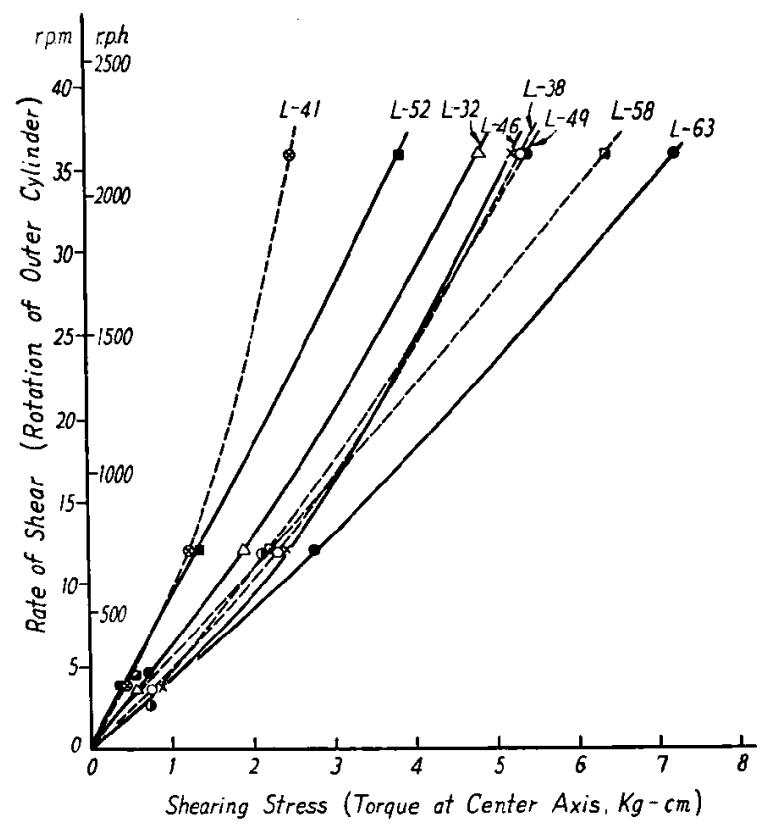

Fig. 6 Fluidity curves.

However, a high degree of blowing induces brittleness, and it is believed to decrease the rupture strength. On the whole, the rupture strength is highest for Arabian Light series, moderate for Asahigawa Light and Heavy series and Arabian Heavy series. The values of rupture strength for these series are of the order of $10 \mathrm{~kg} / \mathrm{cm}^{2}$, but Kurokawa and Higashiyama series show the values of about $5 \mathrm{~kg} / \mathrm{cm}^{2}$. These results indicate that asphalts of good low-temperature ductility do not necessarily show good brittleness strength at low temperatures. Moreover, the rupture strength of good low-temperature ductility samples, prepared from Arabian vacuum residue by molecular distillation, solvent extraction or blending procedures, has a low values of about $5 \mathrm{~kg} / \mathrm{cm}^{2}$ as shown in Table 1.

Concerning the temperature dependence of rupture strength, the critical rupture temperature is
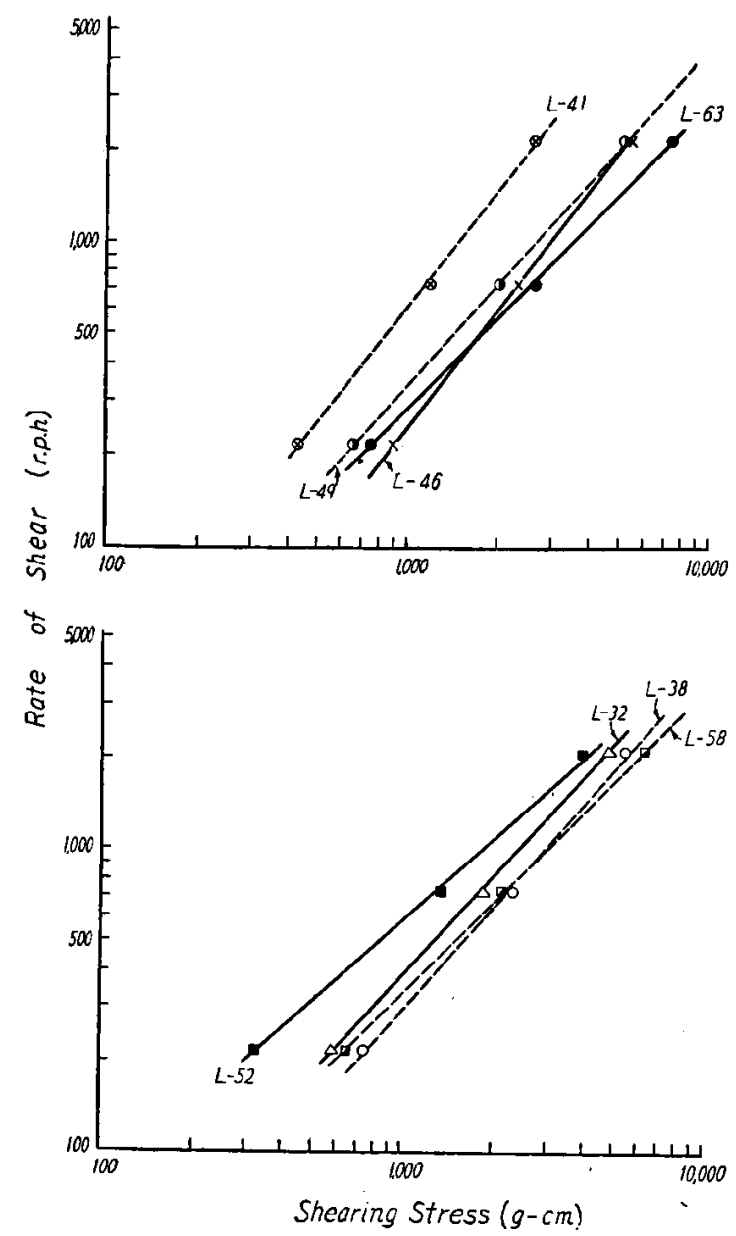

Fig. 7 Logarithmic relation between shearing stress and rate of shear.

the lowest for Arabian Light series. On the other hand, the rupture strength of this series is high at this temperature. It may be noted that the relative order of asphalt expressed by rupture strength is somewhat dependent upon the temperature.

When fluidities at the softening points are com. pared, some differences can be seen even in the asphalts which are but slightly processed, and their values approach 1 in the order of Arabian, Asahigawa, Kurokawa, and Higashiyama. Therefore, the sources of asphalt themselves are believed to be different in their gel characteristics.

Moreover, as this order corresponds practically to the magnitude of rupture strength at $0^{\circ} \mathrm{C}$, the colloidal structure of asphalt can be postulated to be a factor which governs the strength.

The higher the softening point, the lower will be the value of " $\mathrm{C}$ ", but the lowering is more remarkable for the Light series than for the Heavy 


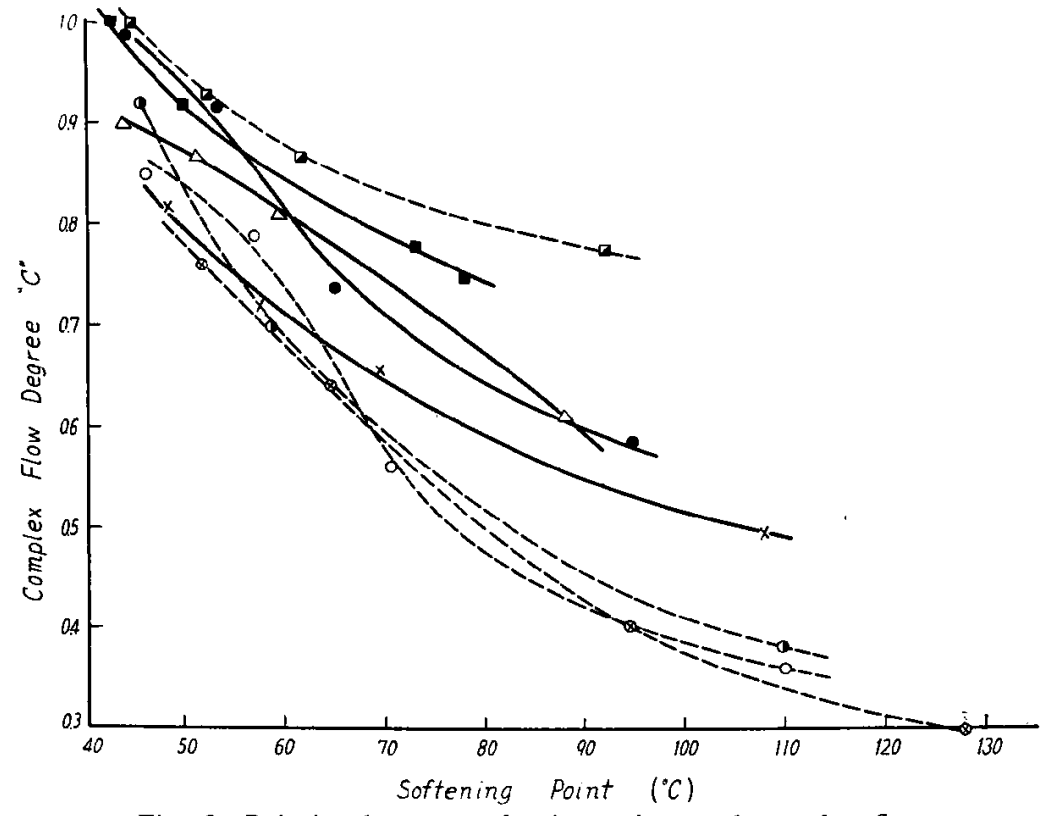

Fig. 8 Relation beween softening points and complex flow.

ones. Only for the Higashiyama series, however, the decreasing of " $\mathrm{C}$ " is slight, and the inclinations of the Heavy and the Light series are different from the others.

For the samples of similar softening points, " $\mathrm{C}$ " corresponds to the rupture strength in general; however, Kurokawa Light series shows considerably lower rupture strength than is expected from its fluidity.

However, it may not be possible to explain this rupture rigorously, because the molecules themselves, which are produced during preparation (e.g. by dehydrogenation-polymerization) may strongly influence it. in addition to the effects of colloidal nature, temperature, and rate of deformation. Asphalt is so complex constitutionally and colloidally, that more studies are necessary to obtain more definite conclusions.

\section{Conclusions}

The colloidal structure of asphalt is postulated to be a factor that governs its low-temperature brittleness. It can be estimated, to a certain extent, from its non-Newtonian fluidity at the softening point, and is believed to be dependent on the source of asphalt.

The low-temperature ductility in JIS paving grades of asphalt does not show any direct correspondence with the rupture strength at the low temperature. Asphalt of lower ductility at the low temperatures often possesses a higher brittleness strength.

A further study will be required to establish a firmer relationship between the rupture strength and colloidal structure.

\section{References}

(1) R.N. Traxler et al. Ind. Eng. Chem. Anal. Ed., 14340 (1941); Ind. Eng. Chem, 36823 (1944).

\section{Acknowledgment}

We are indebted to $\mathrm{Mr}$. H. Aida of Chem. Res. Inst. of Kyoto Uuiversity for his suggestions, and to Nippon Oil Co. for permission to publish this work. 